\title{
CARACTERIZAÇÃO FÍSICO-QUÍMICA DE RESÍDUOS SÓLIDOS DA INDÚSTRIA DE PAPEL E CELULOSE PARA FINS ENERGÉTICOS
}

\author{
M. R. C. da SILVA'1 , A. da S. GURGEL ${ }^{1}$, S. L. F. ANDERSEN ${ }^{2}$ \\ ${ }^{1}$ Universidade Federal da Paraíba, Departamento de Energias Alternativas e Renováveis \\ ${ }^{2}$ Universidade Federal da Paraíba, Departamento de Energias Alternativas e Renováveis \\ E-mail para contato: silvia@cear.ufpb.br
}

\begin{abstract}
RESUMO - Resíduos sólidos (biomassa) da indústria de papel e celulose foram selecionados e caracterizados para utilização como fonte alternativa e renovável de energia. Os resíduos estudados foram a fibra do engrossador e o resíduo de limpeza do decantador do tratamento de efluentes. As biomassas foram caracterizadas por meio de análise imediata, TGA/DTG e MEV, e o comportamento pirolítico foi verificado. O poder calorífico foi calculado e

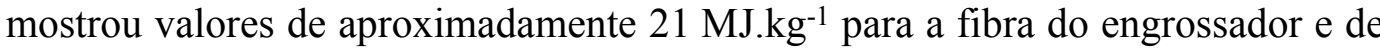

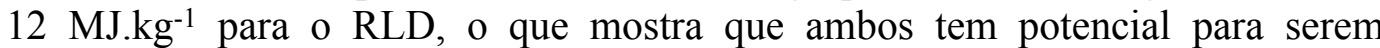
utilizados em processos de conversão térmica. A análise de TGA foi utilizada para estudar o comportamento pirolítico das amostras e mostrou perdas de massa referentes à liberação de umidade, material volátil mais leve (degradação de celulose e hemicelulose) e material volátil mais pesado (lignina). A morfologia das amostras foi analisada por meio de MEV. Ambos os resíduos são potenciais matéria prima para processos de conversão térmica visando o aproveitamento energético.
\end{abstract}

\section{INTRODUÇÃO}

Ao longo dos anos o consumo energético vem aumentando significativamente no mundo, em especial no Brasil, pois a demanda (cada vez maior) tem sobressaído à oferta de energia. Fatores como a escassez de combustíveis fósseis e as mudanças climáticas em várias regiões do planeta, também têm contribuído para a necessidade em se buscar soluções para uma crise energética eminente.

É inquestionável que o país já tenha evoluído nas últimas décadas, em relação à adoção de fontes renováveis de energia, em especial desde a primeira crise do petróleo ocorrida em 1973, quando cerca de $80 \%$ do combustível era importado; e com a crise hídrica ocorrida em 2001, quando 90\% da energia gerada era proveniente da água. (EPE, 2008; VOICTH, 2009). Dentre as fontes renováveis mais utilizadas, têm-se: a energia eólica, gerada pela força dos ventos; a biomassa, produzida por meio da matéria orgânica de origem vegetal e animal; a energia solar, produzida pela captação da luz emitida pelo sol; e a hidráulica, gerada a partir da água, dentre outras (PACHECO et al., 2006).

A biomassa é uma fonte de energia limpa, renovável e de uso extremamente vantajoso para o país; tendo em vista, que além de suprir o déficit energético, pode minimizar 
problemas sociais (como criação de novos postos de trabalho e aumento de renda) e ambientais, sobretudo quanto às emissões de $\mathrm{CO}_{2}$ (BACCHI et al., 2006).

Uma de suas principais vantagens do uso energético da biomassa é que seu aproveitamento pode ser feito por meio da combustão em caldeiras e fornos comuns, e como grande desafio hoje está o desenvolvimento tecnológico em conversões que podem ser mais eficientes, como a gaseificação e a pirólise (CCEE, 2015).

A indústria de celulose e papel é uma das indústrias mais ricas da economia brasileira, se comparada aos demais segmentos da economia, além de ser considerada pelo mercado nacional, como "ambientalmente correta", por trabalhar apenas com madeira de reflorestamento (IBA, 2014).

Os grandes avanços na biotecnologia e silvicultura permitiram também que o país se tornasse referência no cenário mundial de celulose, devido, principalmente, à alta produtividade da cultura (sendo necessárias cerca de 20 árvores de eucalipto são cortadas para produzir uma tonelada de celulose); embora o pinus venha ganhando destaque, a espécie mais utilizada é o eucalipto (SANTOS, et al., 2001).

O processo de fabricação da polpa celulósica pode ser por meios: mecânicos, semiquímicos e químicos. No processo mecânico, as fibras de celulose, são liberadas por processos físicos, sem ou com uma pequena extração de outros componentes da fibra, como a resina, lignina e carboidratos; essa extração tem um alto rendimento operacional $(90 \%$ a $95 \%$ em polpa), utilizada na produção de papéis, devido à baixa resistência e estabilidade. Nos semiquímicos, o processo é misto, ou seja, os cavacos são cozidos em meio alcalino ou neutro, seguidos de processos físicos para a extração de fibras celulósicas; o rendimento é médio nesses processos $(70 \%$ a $80 \%$ em polpa). Já no processo químico, o rendimento operacional é baixo ( $46 \%$ a $56 \%$ ), geralmente utilizam-se madeiras macias, com a extração das fibras feitas em meio ácido ou alcalino, os resultados das fibras obtidas são longas e utilizadas na produção de papéis com uma alta qualidade (MAEDA et al., 2010).

No processo, após o corte das árvores, começa o preparo da madeira (descascamento), logo depois as toras são picadas em cavacos com tamanhos iguais e vai para a polpação, facilitando a separação das fibras. Nessas fibras encontra-se a celulose que é o principal insumo para a fabricação de papel e também a lignina que proporciona a rigidez na madeira, quanto maior a quantidade de lignina existente maior será a quantidade de reagentes usados para o cozimento e branqueamento da celulose. O processo mais utilizado é o Kraft, devido a sua eficiência na recuperação dos produtos químicos usados na digestão da matéria-prima aplicada, resultando na pasta celulósica, possuindo coloração marrom devido à presença de lignina residual. Para obter polpas brancas, é necessário remover a lignina que está fortemente ligada às fibras (MIRANDA et al., 2008).

Em empresas que produzem papeis reciclados, o processo de fabricação do papel começa com a seleção das aparas, que passam pelo processo de retirada de impurezas pesadas (processo de desagregação), no entanto a massa ainda passa pelo peneiramento. Após o sistema de limpeza da massa, ela passa pelo processo de engrossamento de massa, onde ocorre a recuperação das fibras. Normalmente esse engrossador é composto por um tambor cilíndrico que possui armação feita com material corrosivo, sendo revestido com uma tela metálica fina (BONA et al., 2004). A utilização de decantadores para a extração de líquidos provenientes da matéria-prima úmida é fundamental para o melhor aproveitamento dessa matéria. 
O segmento de papel e celulose, bem como o tratamento de efluentes do segmento, produz uma infinidade de resíduos (a exemplo das cascas de árvores, do licor negro, além dos resíduos de limpeza) e impactos ambientais (como a monocultura) (SOARES et al., 2006).

Existem estudos de utilização de resíduos sólidos industriais como fonte de energia (Zhang, et al., 2010), especialmente em se tratando de conversão térmica, como a combustão, a gaseificação e a pirólise (Lin, et al., 2014; Lou, et al., 2012).

Neste trabalho foram selecionados dois resíduos sólidos de uma indústria de papel e celulose da região sudeste do Brasil. A indústria também tem o processo de reciclagem de papel e embalagens Tetra Pak ${ }^{\circledR}$. Os resíduos selecionados foram a fibra do engrossador e o resíduo de lodo do decantador do tratamento de efluentes da indústria. O objetivo do trabalho foi caracterizar físico-quimicamente e avaliar o potencial de utilização dos resíduos sólidos selecionados da indústria de celulose e papel como fonte alternativa e renovável de energia, utilizando processos de conversão térmica de biomassa e avaliando as propriedades de pirólise.

\section{MATERIAL E MÉTODOS}

Para este trabalho foram selecionados dois resíduos sólidos (biomassas): fibra do engrossador e resíduos de limpeza do decantador (RLD), ambos provenientes de uma indústria de papel e celulose da região sudeste do Brasil.

As amostras de fibra do engrossador foram obtidas no processo de maturação em um engrossador no processo de reciclagem e o RLD foi coletado da limpeza do decantador da estação de tratamento de efluentes. As amostras foram coletadas em julho de 2014. Antes das análises as amostras foram secas em estufa a $105{ }^{\circ} \mathrm{C}$, trituradas e peneiradas até tamanho da partícula inferior a 100 mesh.

Os resíduos sólidos foram caracterizados por meio de análise imediata, análise termogravimétrica (TGA/DTG) para estudo do comportamento da pirólise, e microscopia eletrônica de varredura (MEV), para avaliar a morfologia. O poder calorífico superior (PCS) foi calculado com base numa equação empírica (DEMIRBAS, 1997) a partir da análise imediata, no qual a equação é função do teor de carbono fixo (CF) e o teor do material volátil (MV), conforme equação 1 .

$\mathrm{PCS}=0,312(\mathrm{CF})+0,1534(\mathrm{MV})\left[\mathrm{MJ}_{\mathrm{kg}}{ }^{-1}\right]$

Para a análise imediata, o teor de cinzas, o material volátil e o carbono fixo foram determinados utilizando as normas ASTM (E871-82, D1102-84 e E872-82). O carbono fixo foi calculado por diferença. A TGA/DTG foi realizada utilizando o equipamento TA, modelo TGA Q50, sob atmosfera inerte de $\mathrm{N}_{2}$, a uma vazão constante de $50 \mathrm{~mL}$. $\mathrm{min}^{-1}$, e massa de $10 \mathrm{mg}$ de amostra. As análises foram realizadas utilizando o programa de temperatura a partir da temperatura ambiente até $900{ }^{\circ} \mathrm{C}$ mantidos a uma taxa de aquecimento de $10{ }^{\circ} \mathrm{C} \cdot \mathrm{min}^{-1}$.

A análise de microscopia eletrônica de varredura (MEV) foi realizada para avaliar a morfologia no microscópio marca Oxford, modelo 7353.

\section{RESULTADOS E DISCUSSÃO}

A Tabela 1 mostra as propriedades físico-químicas do RLD e da fibra do engrossador. 


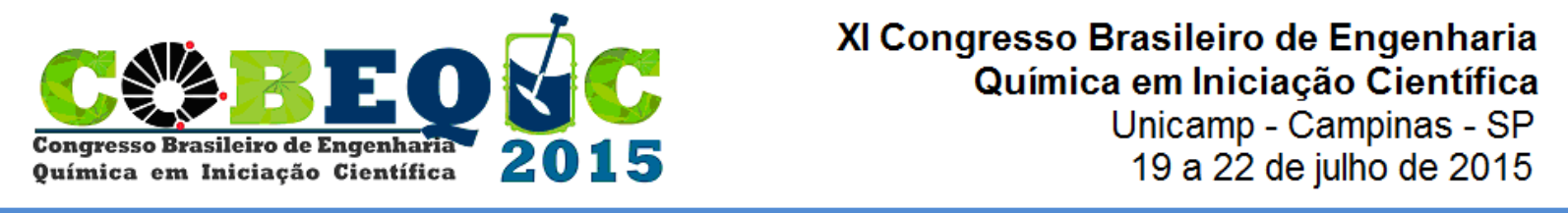

Tabela 1 - Propriedades físico-químicas das biomassas

\begin{tabular}{ccc}
\hline & Fibra do Engrossador & RLD \\
\hline Material Volátil* $[\%, \mathrm{~m} / \mathrm{m}]$ & 80,26 & 40,25 \\
Cinzas $^{*}[\%, \mathrm{~m} / \mathrm{m}]$ & 8,98 & 38,06 \\
Carbono Fixo* $[\%, \mathrm{~m} / \mathrm{m}]$ & 28,72 & 21,69 \\
Poder Calorífico Superior ${ }^{*}\left[\mathrm{MJ} . \mathrm{kg}^{-1}\right]$ & 21,27 & 12,94 \\
\hline
\end{tabular}

*base seca; ${ }^{1}$ calculado utilizando a equação (1).

Observa-se que o teor de material volátil da fibra do engrossador é elevado: 80,26\%, o que é comum em biomassas e demonstra uma possível reatividade e degradação rápida do material. O RLD apresentou teor de material volátil de 40,25\%.

O teor de cinzas da fibra do engrossador foi de $8,98 \%$ enquanto que no RLD o teor de cinzas foi de $38,06 \%$. Um menor teor de cinzas colabora para o aumento do poder calorífico (PC). O PCS da fibra do engrossador é de 21,27 MJ.kg-1, indicando uma boa possibilidade de aproveitamento desse resíduo como fonte de energia, especialmente em processos de conversão térmica. O RLD apresentou PCS de 12,94 MJ. $\mathrm{kg}^{-1}$, que é inferior ao da fibra do engrossador, já que o teor de cinzas é elevado. Lou, et al.(2012) caracterizaram lodo de papel e celulose (descoloramento) e encontraram valor similar de 10,35 MJ.kg-1.

As propriedades de pirólise dos resíduos estão representadas nas Figuras 1 e 2, as quais mostram as curvas de TGA/DTG. No estudo de pirólise muitas vezes é possível caracterizar a biomassa e observar a liberação de hemicelulose, celulose e lignina, que são liberados em temperaturas diferentes (Zhang, et al., 2014; Lou et al., 2012). O maior pico geralmente representa a liberação do material volátil mais leve, sendo que os demais picos representam a liberação de material volátil mais pesado.

Figura 1 - TGA/DTG da Fibra do Engrossador

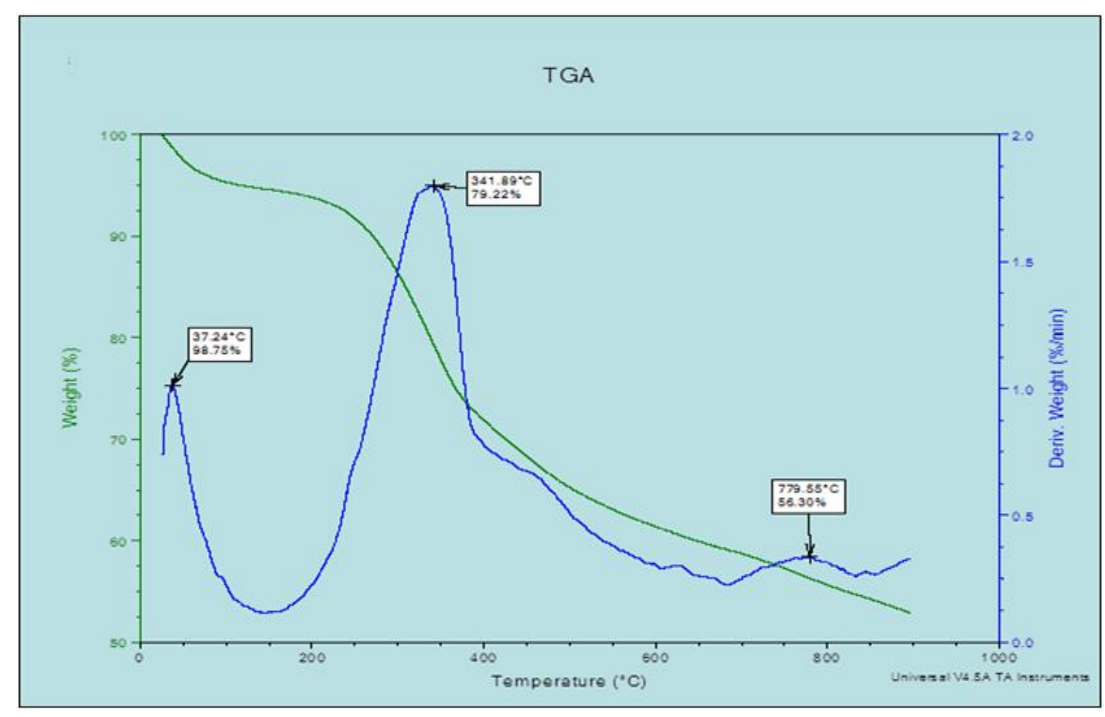

No caso da fibra do engrossador (Figura 1), verifica-se a presença de uma pequena curva no início, referente à perda da umidade da amostra que se estabiliza entre os $90^{\circ} \mathrm{C}$. A 
maior curva encontra-se entre $200^{\circ} \mathrm{C}-400^{\circ} \mathrm{C}$, com pico em aproximadamente $350{ }^{\circ} \mathrm{C}$ caracterizando a perda de material volátil (geralmente a degradação de celulose). Outro pico em aproximadamente $647^{\circ} \mathrm{C}$ ocorre a perda de material volátil mais pesado. No total, a perda de material volátil foi de $89,65 \%$, o que apresenta uma equivalência com a porcentagem de material volátil obtida por meio da análise imediata de $80,26 \%$. A diferença também se dá devido à diferenças de metodologia.

Figura 2 - TGA/DTG do RLD

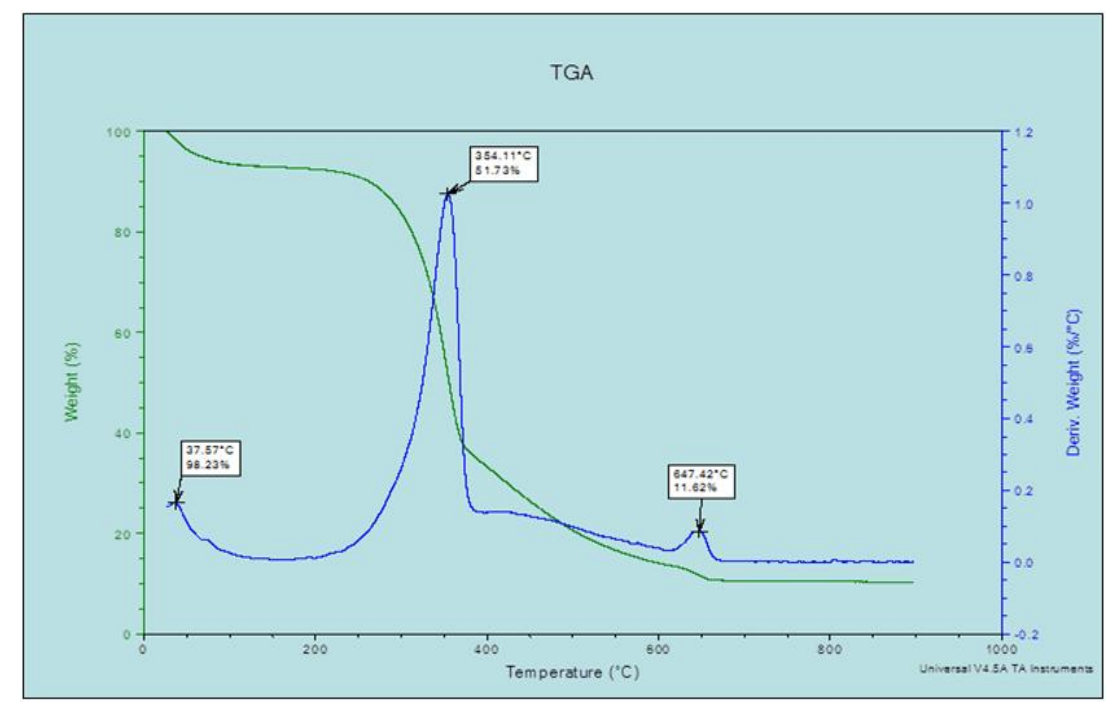

Nas curvas correspondentes ao RLD (Figura 2), verifica-se também a presença de uma curva no início referente à perda de umidade, entre os $30^{\circ} \mathrm{C}-120^{\circ} \mathrm{C}$. A temperatura de pico nessa faixa foi aos $38^{\circ} \mathrm{C}$. O maior pico encontra-se a aproximadamente $342{ }^{\circ} \mathrm{C}$, caracterizando perda de material volátil mais leve. A segunda perda de massa é mais lenta e apresenta duas etapas, o que causou um "ombro" na curva de DTG. Após essa etapa ocorreu continuamente uma perda de massa lenta e constante representando a degradação de material volátil mais pesado, como a lignina, que tem a sua degradação em temperaturas acima de $500{ }^{\circ} \mathrm{C}$ (Garcia-Maraver, et al. 2013).

Analisando a porcentagem de decréscimo total de massa $(47,08 \%)$ - correspondente ao material volátil da biomassa, e comparando com o mesmo critério calculado pela análise imediata (40,25\%), pode-se concluir que ambos os valores estão em consonância entre si, com uma pequena margem de erro. Zhang et al.(2009) encontrou um teor de 48,9\% de material volátil para lama de depuração digerida (processo de papel e celulose) e Monte et al. (2008) constatou um teor de $33 \%$ de composto volátil para o lodo primário e $48 \%$ para o lodo biológico do tratamento de efluentes de uma indústria de papel. Esses resultados obtidos pelos autores aproximam-se dos discutidos neste trabalho.

Ao analisar a morfologia, a Figura 3 (a) mostra a imagem de MEV da amostra de fibra do engrossador. Observa-se uma morfologia mais uniforme sem presença de poros pequenos, entretanto as partículas são irregulares e aglomeradas características de fibras.

Conforme mostra a Figura 3 (b), é possível observar que as partículas não são uniformes e possuem aglomeração de forma mais sólida. Ambas as morfologias são adequadas para que as biomassas sejam utilizadas em processos de conversão térmica. 
Figura 3 - MEV dos resíduos sólidos: (a) fibra do engrossador; (b) RLD.

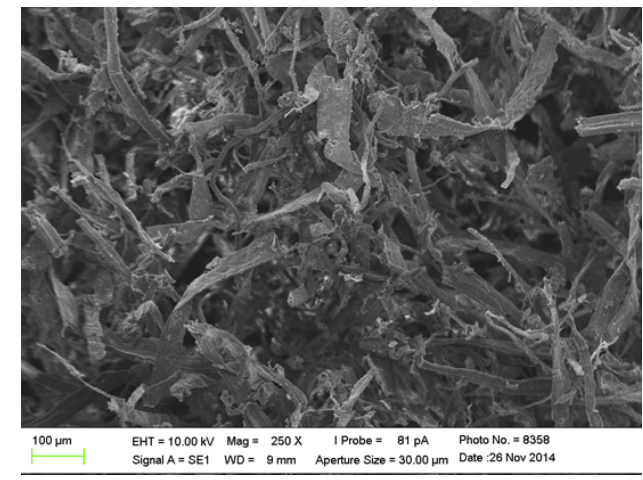

(a)

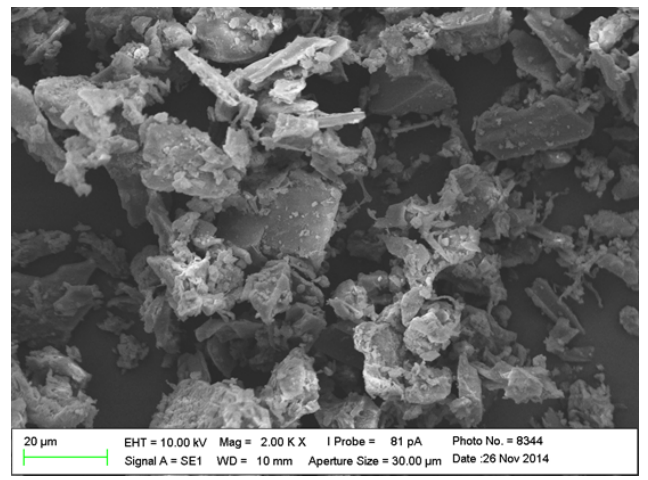

(b)

\section{CONCLUSÃO}

Neste trabalho os resíduos: fibra do engrossador e o RLD da indústria de papel e celulose foram caracterizados físico-quimicamente para a avaliação da possibilidade de utilização como fontes renováveis de energia. Foi possível observar que ambas as biomassas apresentaram teores elevados de material volátil $(80,26$ e $40,25 \% \mathrm{~m} / \mathrm{m}$ respectivamente) o que é comum para biomassas e favorável para a utilização em processos de conversão térmica. Os poderes caloríficos confirmam o resultado (21 e $\left.12 \mathrm{MJ} \cdot \mathrm{kg}^{-1}\right)$ para a fibra do engrossador e o RLD. O comportamento de pirólise foi estudado por meio de TGA/DTG e mostrou que existe liberação de umidade, material volátil leve (hemicelulose e celulose) e mais pesado (lignina). A morfologia das amostras foi observada por meio de MEV e verificou-se que as biomassas podem ser aplicadas em processos de conversão térmica. Em suma, os resíduos estudados são potenciais fontes de energia alternativa e renovável que podem ser utilizadas na própria indústria.

\section{REFERÊNCIAS}

BACCHI, M.R.P. Brasil- gerando energia de biomassa, limpa e renovável. Disponível em: < http://cepea.esalq.usp.br/>. Acesso em 24 de janeiro de 2015.

BRASIL. ANVISA. Dispõe sobre resíduos sólidos. Disponível em: $<\mathrm{http}: / / \mathrm{s}$.anvisa.gov.br/wps/s/r/bhPP $>$. Acesso em: 15 de janeiro de 2015.

BRASIL. Resolução CONAMA n 001, de 23 de janeiro de 1986. Dispõe sobre critérios básicos e diretrizes gerais para a avaliação de impactos ambientais. Disponível em: $<$ http://www.mma.gov.br/port/conama/legiabre.cfm?codlegi=23>. Acesso em: 01 de fevereiro de 2015.

BONA, F. R. Estágio Supervisionado em engenharia de produção IPEL- Indaial papel embalagens lida. Santa Catarina: FURB, 2004.

Câmera de comercialização de energia elétrica, CCEE. Dispõe sobre fontes. Disponível em: $<$ http://www.ccee.org.br/portal/faces/pages publico/ondeatuamos/fontes? afrLoop $=3346855666761095 \# \% 40 \% 3 \mathrm{~F}$ afrLoop $\% 3 \mathrm{D} 3346855666761095 \% 26$ adf .ctrl-state\%3Dojw81s8nc 45>. Acesso em: 28 de janeiro de 2015. 


\section{Congresso Brasileiro de Engenharia Química em Iniciação Científica Unicamp - Campinas - SP 19 a 22 de julho de 2015}

EPE. Contexto mundial e preço do petróleo: uma visão de longo prazo. Disponível em: $<$ http://www.epe.gov.br/Petroleo/Documents/Estudos_29/Contexto\%20Mundial\%20e $\% 20 \mathrm{Pre} \% \mathrm{C} 3 \%$ A7o\%20do\%20Petr\%C3\%B3leo\%20Uma\%20Vis\%C3\%A3o\%20de\%20Longo\%20Prazo.pdf $>$. Acesso em: 18 de janeiro de 2015.

GARCIA-MARAVER, A.; SALVACHÚA, D.; MARTÍNEZ, M.J.; DIAZ, L.F. ZAMORANO, M. Analysis of the relation between the cellulose, hemicellulose and lignin content and the thermal behavior of residual biomass from olive trees. Waste Management, v. 33, p. 2245-2249, 2013.

Indústria Brasileira de Árvores, IBÁ. Indicadores de desempenho nacional de árvores plantadas referentes ao ano de 2013. Disponível em: $<$ http://www.bracelpa.org.br/shared/iba 2014 pt.pdf $>$. Acesso em: 29 de janeiro de 2015.

LIN, Y.; MA, X.; YU, Z.; CAO, Y. Investigation on thermochemical behavior of co-pyrolysis between oilpalm solid wastes and paper sludge. Bioresource Technology, v. 166, p. 444-450, 2014.

LOU, R.; WU, S.; LV, G.; YANG, Q. Energy and resource utilization of deinking sludge Pyrolysis. Applied Energy, v. 90, p. 46-50, 2012.

MAEDA, Shizuo; EPITÁGORAS, Rodson Oliveira Costa; HELTON, Damin da Silva. Documento 202: Uso de resíduos da fabricação de celulose e papel e da reciclagem de papel. Embrapa Florestas. Disponível em: < http://ainfo.cnptia.embrapa.br/digital/bitstream/item/24482/1/Doc202.pdf $>$ Acesso em: 01 de novembro de 2014.

MIRANDA, R. E. dos S. de. Impactos ambientais decorrentes dos resíduos gerados na produção de papel e celulose. Rio de Janeiro: UFRRJ, 2008.

MONTE, M. C.; FUENTE, E.; BLANCO, A.; NEGRO, C. Waste management from pulp and paper production in the European Union. Waste Management, v. 29, p. 293-308, 2009.

PACHECO, F. Energias Renováveis: Breves conceitos. Bahia: Editora Conjuntura e Planejamento, 2006.

RECKAMP, J. M.; GARRIDO, R. A.; SATRIO, J. A. Selective pyrolysis of paper mill sludge by using pretreatment processes to enhance the quality of bio-oil and biochar products. Biomass and Bioenergy, v.71, p. 235-244, 2014.

RIDOUT, A. J.; CARRIER, M.; GORGENS, J. Fast pyrolysis of low and high ash paper waste sludge; Influence of reactor temperature and pellet size. Journal of Analytical and Applied Pyrolysis, v. 111, p. 64-75, 2015.

SANTOS, C. P.; REIS, I. N. dos.; MOREIRA, J. E. B.; BRASILEIRO, L. B. Papel: Como se fabrica?. Química nova na escola, 2001.

SOARES, T. S.; CARNEIRO, A. de C. O.; GONÇAlVES, E. de O.; LELlES, V. J. G. de. Uso da biomassa florestal na geração de energia. Revista científica eletrônica de engenharia florestal, São Paulo, ano 5, $\mathrm{n}$ 9, agosto de 2006. Disponível em: < http://www.agencia.cnptia.embrapa.br/Repositorio/florestal1_000gapwcajw02wx5ok04xjloyxd3fpu2 .pdf>. Acesso em: 10 de janeiro de 2015.

VOICHT, G. Apagão de 2001 Disponível em: $<$ http://www.gazetadopovo.com.br/apagaonobrasil/conteudo.phtml?id=943486>. Acesso em: 06/12/2014.

ZHANG, J.; FENG, L.; WANG, D.; ZHANG, R.; LIU, G.; CHENG, G. Thermogravimetric analysis of lignocellulosic biomass with ionic liquid pretreatment. Bioresource Technology, v. 153, p. 379-382, 2014.

ZHANG, L.; XU, C.; CHAMPAGNE, P. Energy recovery from secondary pulp/paper-mill sludge and sewage sludge with supercritical water treatment. Bioresource Technology, v. 101, p. 2713-2721, 2010. 